\title{
EDITORIAL
}

\section{Movimento Nursing Now no Brasil: trajetórias e perspectivas}

A campanha Nursing Now tem como objetivos melhorar a saúde por meio do fortalecimento do perfil e do status da enfermagem em todo o mundo, sendo que o empoderamento dos enfermeiros facilita esse processo ${ }^{1}$. Nessa perspectiva, 2020 foi ressignificado como o ano da enfermagem, escolhido para direcionar mudanças sobre investimentos, com a intenção de gerar visibilidade global dessa profissão².

A partir deste movimento, dados foram coletados e sintetizados para caracterizar e orientar os avanços, desafios e perspectivas futuras que permeiam os profissionais da enfermagem, por intermédio da programação mundial do Nursing Now e da publicação do relatório sobre a enfermagem no mundo, denominado "The State of the World's Nursing 2020 Report", em parceria com a Organização Mundial da Saúde e o Internacional Council of Nurses ${ }^{3}$. A proposta principal dessa publicação será impulsionar e direcionar os investimentos em enfermagem, por meio de evidências científicas, para futuras ações de políticas públicas voltadas à formação e preparo desses profissionais para as melhores práticas de assistência de saúde no âmbito mundial ${ }^{3}$.

Dentre os dados apresentados, destaca-se a enfermagem como força de trabalho em maior quantidade em todo o mundo e de profissionais em faixas etárias cada vez mais jovens ${ }^{3}$. Contudo, ainda é incipiente as oportunidades para que o enfermeiro obtenha espaço na tomada de decisões no que concerne as políticas de saúde, sociais e econômicas ${ }^{1}$. Isso leva a reflexões sobre como será o futuro da classe profissional, e ao questionamento: As habilidades e competências necessárias estão sendo desenvolvidas? Como garantir a visibilidade do enfermeiro neste contexto?

O Nursing Now's Nightingale Challenge visa direcionar investimentos a jovens enfermeiros e parteiras, permitindo que se tornem mais ativos, criativos e líderes na força de trabalho, aprimorando a assistência ao cliente e colocando-os no centro do enfrentamento dos desafios de saúde do século XXI².

Neste cenário, a liderança emerge como competência inerente ao enfermeiro, sendo considerada importante ferramenta para o alcance dos objetivos organizacionais e da equipe; além da melhoria da assistência prestada ao cliente. É preciso então, como enfermeiros, liderar para mudar?

Para que os alcances globais do movimento Nursing Now sejam efetivados, torna-se imprescindível a valorização da profissão como prática transformadora do cuidado, da assistência integralizada e do reconhecimento do papel central do enfermeiro na liderança e elaboração de estratégias de cuidados e políticas públicas.

Desse modo, a união de forças dos diferentes campos da saúde, educação, política, economia e sociedade são necessários, para (re)conhecer e incentivar a prática da Enfermagem embasada na ética, na liderança, no conhecimento científico, na prática clínica e na formação humana, no cuidado com amor, trabalho em equipe e autonomia profissional.

Também, para se atingir o que propõe o movimento, é preciso que a construção do saber em Enfermagem seja pautada na visão bio-psico-social-espiritual do ser e, consequentemente, na redescoberta profissional, por meio do cuidado, da ciência, do uso de tecnologias, filosofia e profundas mudanças nas perspectivas da liderança.

Acredita-se que as discussões levantadas acerca do tema possam contribuir para maior visibilidade do Movimento Nursing Now, incentivar e despertar presentes e futuros enfermeiros, assim como empoderar acadêmicos, pós-graduandos, técnicos de enfermagem para a relevância e impacto da Enfermagem para a saúde, para o bem-estar social, ambiental e espiritual no Brasil e no mundo! 


\section{REFERÊNCIAS}

1. Kennedy A. Wherever in the world you find nurses, you will find leaders. Rev Latino-Am Enfermagem. 2019; 27:e3181. [Acesso 05 fev 2021]; Disponível em: https://www.scielo.br/pdf/rlae/v27/1518-8345-rlae-27-e3181.pdf DOI: http://dx.doi.org/10.1590/1518-8345.0000.3181

2. Bayliss-Pratt L, Daley M, Bhattacharya-Craven A. Nursing Now 2020: the Nightingale Challenge. International Nursing Review 2020; 67(1):7-10. [Acesso 05 fev 2021]; Disponível em: https://pubmed.ncbi.nlm.nih.gov/32083727/ DOI: 10.1111/inr.12579

3. World Health Organization. State of the World's Nursing 2020: investing in education, jobs and leadership. 2020. World Health Organization. [Acesso 05 fev 2021]; Disponível em: https://apps.who.int/iris/handle/10665/331677

Boa Leitura!

\section{Gianna Fiori Marchiori}

Enfermeira. Mestre e Doutora em Atenção à Saúde. Professora Substituta do Departamento de Enfermagem na Assistência Hospitalar da Universidade Federal do Triângulo Mineiro (UFTM), Uberaba, MG, Brasil.

Divanice Contim

Enfermeira. Mestre em Enfermagem. Doutora em Ciências. Professora Associada do Curso de Graduação em Enfermagem e do Programa de Pós Graduação em Atenção à Saúde da UFTM, Uberaba, MG, Brasil.

\section{Nayara Paula Fernandes Martins Molina}

Enfermeira. Especialista em Gerontologia. Mestre e Doutora em Atenção à Saúde. Professora Temporária no Departamento de Enfermagem Psiquiátrica e Ciências Humanas da Universidade de São Paulo, SP, Brasil. 